\title{
PENGUJIAN FUNGSIONALITAS, PERFORMA DAN KEAMANAN DENGAN SISTEM PENGUJIAN OTOMATISASI PADA APLIKASI LIKMI HUB
}

\author{
Maria Christina \\ Sekolah Tinggi Manajemen Informatika dan Komputer LIKMI \\ Jl. Ir. H. Juanda no 96 Bandung \\ notden97@gmail.com
}

\begin{abstract}
ABSTRAK
Kebutuhan mahasiswa untuk dapat mengakses informasi kemahasiswaan secara cepat, mudah dan dapat diakses dimanapun menjadi sebuah permasalahan di perguruan tinggi. Penggunan telepon pintar yang mendukung pengembangan aplikasi yang mendukung kebutuhan mahasiswa turut mendukung permasalahan. Untuk itu STMIK LIKMI mengembangkan aplikasi LIKMI HUB yang menyediakan layanan informasi akademik bagi seluruh mahasiswa STMIK LIKMI dengan menggunakan perangkat android.

Supaya aplikasi dapat digunakan sesuai dengan kebutuhan, maka diperlukan beberapa pengujian. Pada penelitian ini, peneliti menguji LIKMI HUB menggunakan sistem otomatisasi dengan menggunakan 3 buah alat pengujian, untuk menguji fungsionalitas, performa dan keamanan dari LIKMI HUB dengan tujuan supaya aplikasi dapat membuat penggunanya merasa nyaman.
\end{abstract}

Kata kunci : LIKMI HUB, Android, Fungsionalitas, Performa, Keamanan

\section{PENDAHULUAN}

Kebutuhan mahasiswa dalam mengakses segala informasi yang dibutuhkan dimanapun dan kapan pun dengan cepat dan akurat sudah menjadi hal yang sangat diperlukan. Terlebih, mahasiswa merupakan aset yang penting dalam suatu perguruan tinggi atau dapat dikatakan sebagai stakeholder perguruan tinggi.

Kemajuan teknologi dan komunikasi saat ini banyak dimanfaatkan oleh banyak perguruan tinggi untuk memberikan kemudahan bagi mahasiswa untuk kegiatannya seharihari, yang didukung dengan penggunaan telepon pintar atau smartphohe.

Pengembangan aplikasi LIKMI HUB dibuat untuk mendukung segala kebutuhan yang dimiliki oleh mahasiswa di STMIK LIKMI yang merupakan sebuah fitur layanan DIGITAL CAMPUS STMIK LIKMI yang menyediakan layanan informasi akademik bagi seluruh mahasiswa STMIK LIKMI dengan menggunakan perangkat android ${ }^{[4]}$. Mahasiswa dapat mengakses seluruh informasi akademik dengan menggunakan username dan password yang telah disediakan.

Oleh karena itu penelitian ini dilakukan untuk meninjau sejauh mana aplikasi yang dikembangkan dapat digunakan dengan akurat baik dari sisi fungsionalitas, performa dan keamanan aplikasi yang dikembangkan. Pengujian dengan menggunakan teknik black box testing ini merupakan pengujian yang dilakukan hanya dengan mengamati eksekusi aplikasi melalui data uji dengan memeriksa fungsionalitas, performa dan keamanan dari aplikasi LIKMI HUB. Pengujian ketiga hal tersebut menggunakan aplikasi pendukung yang dilakukan secara otomatis. 
Berdasarkan hasil pengujian yang dilakukan, maka akan menghasilkan data yang pada akhirnya dapat ditarik kesimpulan apakah aplikasi LIKMI HUB sudah sesuai dengan yang diharapkan.

\section{TUJUAN DAN PERANGKAT PENGUJIAN}

Tujuan penelitian ini adalah untuk mengukur kinerja aplikasi LIKMI HUB dengan menguji secara otomatis untuk fungsionalitas, performa dan keamanan dari aplikasi tersebut.

Perangkat pengujian yang digunakan meliputi 3 buah testing tool, yaitu :

a. Android Studio + Firebase, untuk menguji fungsionalitas dan User Interface pada aplikasi. Dalam pengujian tersebut dibatasi hanya 6 User Interface dengan keseluruhan fungsionalitas yang ada di dalamnya.

b. PCloudy.com, untuk menguji performa aplikasi selular. Certifaya merupakan tools yang digunakan untuk menguji sampai sejauh mana aplikasi menggunakan sumber daya yang ada pada ponsel pintar ${ }^{[5]}$.

c. Immuniweb.com, menguji beberapa aspek keamanan ${ }^{[6]}$.

\section{HASIL PENGUJIAN DAN PEMBAHASAN}

Berdasarkan hasil penelitian yang dilakukan pada July 2019 terhadap 3 website Bapenda di Pulau Jawa, berikut hasilnya :

\section{a. Pengujian Fungsionalitas}

Penggunaan Firebase dan Android Studio dalam menguji beberapa fungsionalitas dan User Interface aplikasi LIKMI HUB dengan harapan semua hal tersebut dapat berjalan dengan lancar dan sesuai dengan yang diharapkan. Karena menggunakan script pengujian yang dibuat di dalam android studio, maka yang dimasukkan ke dalam jurnal ini berupa ringkasan dari hasil pengujian tersebut.

Tabel 1

Pengujian Fungsionalitas

\begin{tabular}{|c|c|c|c|}
\hline No Uji & Nama Uji & Hasil Yang diharapkan & Hasil \\
\hline \multirow[t]{2}{*}{ FT01 } & \multirow[t]{2}{*}{ Login } & Tampil Halaman Login & Valid \\
\hline & & Berhasil Login & Valid \\
\hline \multirow[t]{10}{*}{ FT02 } & \multirow{10}{*}{$\begin{array}{l}\text { Halaman } \\
\text { Utama }\end{array}$} & Menu Jadwal & Valid \\
\hline & & Menu Nilai & Valid \\
\hline & & Menu Absensi & Valid \\
\hline & & Menu Kalender Akademik & Valid \\
\hline & & Menu Promosi & Valid \\
\hline & & Menu Berita & Valid \\
\hline & & Menu Download File & Valid \\
\hline & & Menu Pengumuman & Valid \\
\hline & & Menu Kontak Dosen & Valid \\
\hline & & Menu Ganti Password & Valid \\
\hline \multirow[t]{4}{*}{ FT03 } & \multirow{4}{*}{$\begin{array}{l}\text { Halaman } \\
\text { Jadwal }\end{array}$} & Tab Jadwal Kuliah & Valid \\
\hline & & Tab Jadwal UTS & Valid \\
\hline & & Tab Jadwal UAS & Valid \\
\hline & & Tab Jadwal Sidang & Valid \\
\hline FT04 & Halaman & Muncul Kumulatif Absensi & Valid \\
\hline
\end{tabular}




\begin{tabular}{|l|l|l|c|}
\hline No Uji & Nama Uji & \multicolumn{1}{|c|}{ Hasil Yang diharapkan } & Hasil \\
\hline & Absensi & Valid \\
\hline FT05 & $\begin{array}{l}\text { Halaman } \\
\text { Berita }\end{array}$ & Tampil List Berita & Valid \\
\hline FT06 & $\begin{array}{l}\text { Halaman } \\
\text { Ganti } \\
\text { Password }\end{array}$ & Tampil Halaman Ganti Password & \\
\hline
\end{tabular}

\section{b. Pengujian Performa}

Agar aplikasi dapat berjalan dengan baik, maka diperlukan pengujian terhadap aplikasi, sehingga dapat diketahui kebutuhan minimal dari perangkat keras ponsel pintar yang digunakan. Pengujian aplikasi LIKMI HUB menggunakan alat uji dari Pcloudy.com, dimana aplikasi digunakan selama \pm 125 detik. Hasil pengujiannya dapat dilihat pada tabel 2 .

Tabel 2

Pengujian Performa

\begin{tabular}{|c|c|c|c|}
\hline \multirow{3}{*}{$\begin{array}{l}\text { No Uji } \\
\text { PT01 }\end{array}$} & Nama Uji & Hasil & Kesimpulan \\
\hline & Memory & 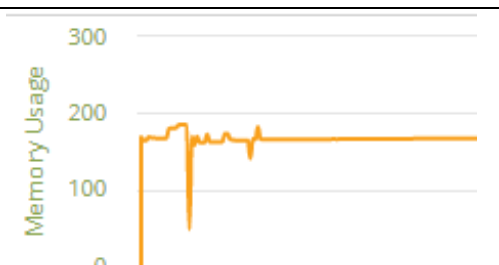 & $\begin{array}{l}\text { LIKMI } r \text { HUB } \\
\text { memerlukan rata-rata } \\
165 \text { MB memory untuk } \\
\text { menjalankan } \\
\text { aplikasinya }\end{array}$ \\
\hline & & 100 & \\
\hline PT02 & $\mathrm{CPU}$ & $\underbrace{}_{0}{ }_{0}^{40}$ & $\begin{array}{l}\text { Penggunaan CPU, rata- } \\
\text { ratanya adalah } 14 \% \text { dari } \\
\text { total } 100 \%\end{array}$ \\
\hline PT03 & Network & - Upload & $\begin{array}{l}\text { Pada saat aplikasi } \\
\text { dijalankan, penggunaan } \\
\text { data untuk upload dan } \\
\text { download hampir sama, } \\
\text { karena adanya proses } \\
\text { pengambilan informasi } \\
\text { mahasiswa dari server } \\
\text { database }\end{array}$ \\
\hline
\end{tabular}




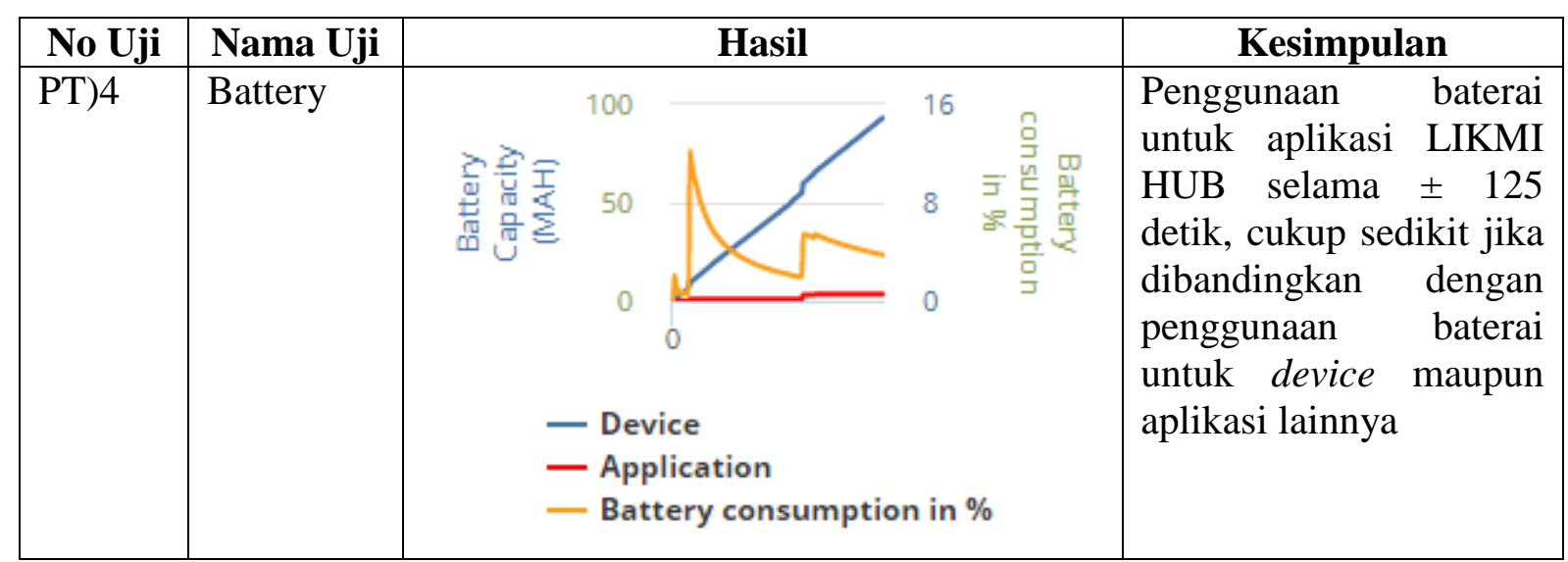

c. Pengujian Keamanan

Berdasarkan hasil pengujian dengan menggunakan Immunweb.com dapat dilihat pada Gambar 1.

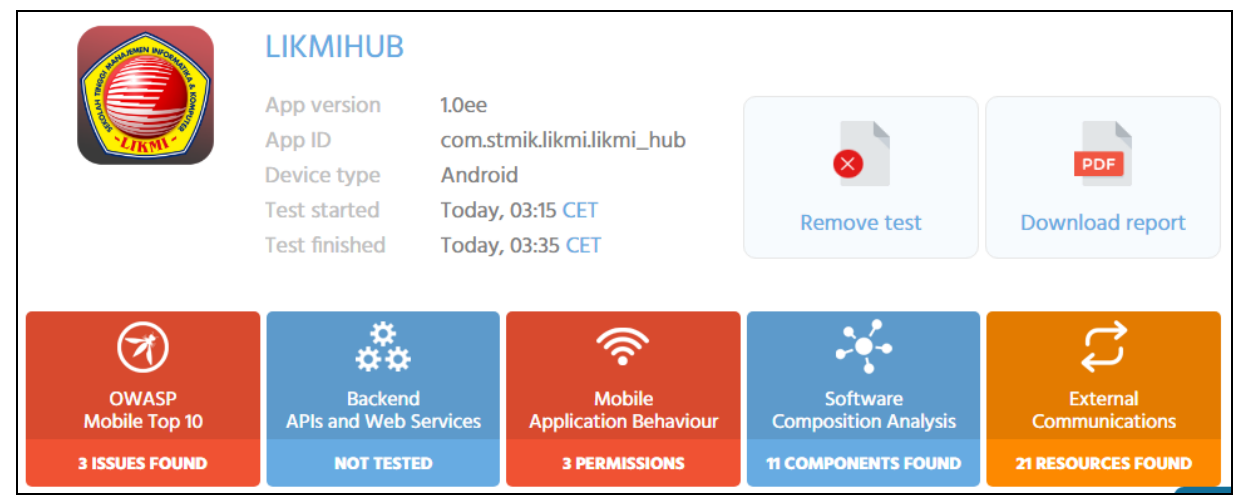

Gambar 1

Pengujian Keamanan

Berikut adalah penjabaran dari gambar yang penting diperhatikan oleh pengembang aplikasi LIKMI HUB, yaitu :

a. Open Web Application Security Project (OWASP), memiliki 3 buah issue dengan tingkat tinggi yang harus diperhatikan kembali oleh pengembang aplikasi LIKMI HUB, yaitu

1) Possible man-in-the-middle attack, yaitu ketika aplikasi terhuhung ke backend (seperti API atau layanan web), verifikasi nama host hilang atau proses implementasi yang tidak tepat, dapat membuat penggunanya rentan terhadap serangan MITM (serangan hacker yang memanfaatkan pengolahan real time transaksi, percakapan atau transfer data lain)

2) Usage of unencrypted HTTP Protocol, yaitu aplikasi menggunakan protokol HTTP untuk mengirim atau menerima data, desain protokol HTTP tidak menyediakan enkripsi data yang dapat dicegat oleh hacker yang berada pada jaringan yang sama sehingga dapat memiliki akses yang sama ke dalam saluran data korban

3) Predictable Random Number Generator, aplikasi menggunakan Random Number Generator (RGN) yang dapat diprediksi, dan aplikasi LIKMI HUB memiliki issue ini yang dapat membahayakan enkripsi data aplikasi atau perlindungan lainnya. 
b. Mobile Application Behaviour, aplikasi LIKMI HUB memerlukan akses ke beberapa fungsi yang dapat membahayakan privasi pengguna, seperti :

1) Kontak

2) Media Penyimpanan

3) GPS

c. Mobile App External Communication, dimana LIKMI HUB terhubung dengan beberapa aplikasi lainnya yang dapat menerima atau mengirimkan data. Gambar 2 menunjukkan hasil pengujiannya. Dapat disimpulkan bahwa hampir sebagaian besar aplikasi eksternal yang terdapat dalam LIKMI HUB tidak memiliki SSL, dan nilai web server security yang tidak terlalu baik (banyak $\mathrm{C}+$ ). Selain itu sangat banyak pula malicious website yang ditemukan

\begin{tabular}{|c|c|c|c|c|}
\hline \multicolumn{5}{|c|}{ Mobile App External Communications } \\
\hline \multicolumn{5}{|c|}{ Static mobile application security test revealed the following remote hosts where the mobile application may send or receive data: } \\
\hline m.facebook.com & 31.13.7. $36: 80$ & $\mathrm{~N}$ & C+ & 1331 malicious websites found \\
\hline instagram.com & $54.15261 .144: 80$ & N & C+ & 1806 malicious websites found \\
\hline loopj.com & 185.199.108.153:80 & $\mathbf{N}$ & B & 5 malicious websites found \\
\hline via.placeholder.com & 45.33.24.119:80 & N & N/A & 1 malicious website found \\
\hline newsapi.org & 167.114.118.40:443 & C+ & C+ & 25 malicious websites found \\
\hline www.youtubecom & $172.217 .13 .206: 443$ & A & A & 1297 malicious websites found \\
\hline twitter.com & $104.244 .42 .1: 80$ & N & C+ & 1002 malicious websites found \\
\hline likmi.000webhostapp.com & 145.14.145.64:80 & N & A & No risks found \\
\hline www.likmiacid & 103.28.12.83:80 & N & N/A & No risks found \\
\hline likmiacid & 103.28.12.83:80 & $\mathrm{N}$ & N/A & No risks found \\
\hline
\end{tabular}

Gambar 2

Keamanan Aplikasi Eksternal

\section{KESIMPULAN DAN SARAN}

Setelah melakukan penelitian dan pengujian secara otomatis pada bagian fungsionalitas, performa dan keamanan pada LIKMI HUB, maka dapat ditarik kesimpulan bahwa :

a. Secara fungsionalitas, LIKMI HUB sudah bekerja dengan baik dan semua fungsi dapat berjalan sesuai dengan kegunaannya.

b. LIKMI HUB memiliki performa yang baik pada saat aplikasi digunakan, sehingga tidak memberatkan ponsel pintar yang digunakan.

c. Dari sistem keamanan, terdapat beberapa hal yang harus diperhatikan dan diperbaiki oleh pengembang aplikasi LIKMI HUB, terlebih untuk penggunaan aplikasi ekternal yang dimasukkan ke dalam aplikasi.

\section{DAFTAR PUSTAKA}

[1] Sommervile, I. Software Engineering Ninth Edition. Addison-Wesley, 2011.

[2] Android Studio Developer, https://developer.android.com/ diakses pada tanggal 30 November 2019 
[3] Firebase console dan documentation, https://console.firebase.google.com/u/0/project/hub-likmi/overview diakses pada tanggal 30 November 2019

[4] https://stmiklikmi.ac.id/2018/09/22/likmi-hub/

[5] Test Run https://Certifaya.PCloudy.com/ diuji 25 November 2019

[6] Test Run https:// https://www.immuniweb.com/mobile/?id=wlWB5QJn/ diuji 5 Desember 2019 